\title{
UN ROMANCE EXTRAÑO
}

ID tal puede calificarse el romance vivido por el conde I.eón Tolstoy en su larga vida conyugal. Fl artista que dió tantas obras insuperadas a la literatura de todos los tiempos fué en su vida privada un hombre atormentado. Se han preocupado de ella los críticos de la obra tolstoyana y siempre la han relacionado estrechamente con sus dificultades conyugales. Las alternativas de su vida en común con su mujer y su larga familia han servido para explicar el origen de las inouietudes del maestro, patentes en las obras que compuso mientras estuvo casado. Pero debe notarse que en este sentido se han dado a la publicidad no pocas afirmaciones que, con un estudio más detenido del carácter de los factores de este matrimonio-él León Tolstoy y ella Sofía Andreevna Bers-, pasan a la categoría de leyendas. Mostrar algo de este interior doloroso, de este intimidad desgarrada por todas las diferencias y las incompatibilidades, a través del diario de la condesa, es lo que pretendemos con estas líneas desaliñadas.

El 23 de Septiembre de 1862 se celebró en Moscú el matrimonio del conde León Tolstoy y de Sofía. El con los antecedentes familiares que son de todos conocido y ella hija del doctor Andrés Evstafievich Bers, viejo amigo de la familia Tolstoy. Contaba el escritor treinta y cuatro años y su mujer sólo diez y ocho. Debemos hacer notar desde luego la diferencia de edad apreciable entre ambos cónyuges que más tarde sería la fuente de no pocos disgustos. El había dejado ya atrás con largueza una juventud borrascosa y altiva, y ella entraba a la mejor época de la juventud ilusionada.

Los escritores que han estudiado la vida de ambos han hecho en ella una cómoda división cronológica que les ha servido para explicar la aparente contradicción de sus dos períodos: uno de felicidad completa, que veremos luego no era tal, durante todo el primer tiempo vivido en Yasnaia Poliana, la posesión familiar de los Tolstoy, y que abarca desde 1862 hasta 1881 , y la otra de disgustos y diferencias, desde 1881 , fecha en que la familia se instaló en Moscú para educar a los hijos, hasta la muerte del conde, comprendidas las diversas épocas en que pasaron en la hacienda de Yasnaia Poliana.

Afortunadamente ambos cónyuges llevaron anotaciones casi diarias de sus existencias, y en ellas se nos muestran los caracteres diferentes e irrec onciliables de cada uno. Fl diario de la 
condesa, llevado con regularidad, interrumpida en períodos a veces superiores a dos años, abarca desde 1862 hasta 1891 y ha sido publicado no ha mucho en París por la Editorial Plon.

No ha prentendido la condesa Tolstoy hacer obra de literatura, pero su libro tiene un interés intenso y nos muestra la verdad diaria de su vida, esa verdad que siempre se calla y que nadie conoce certeramente. Todo el drama de su vida está relatado en las anotaciones disparejas de su diario, y si su marido dejó una obra que el tiempo ha de respetar, el dolor de la esposa silente y sufrida nos inspira pasados tantos años, una emoción inextinguible. Precede al diario una serie de anotaciones relacionadas con el noviazgo y ciertas notas de un cuaderno perdido que debían ayudar a la documentación tolstoyana. Desde las primeras páginas advertimos la contraposición de ambos caracteres. Todo se conjuraba para que fue an felices, pero aun en el noviazgo no lo fueron. Ambas familias, Tolstoy y Bers, complotaban para unir en matrimonio al conde y a una hermana de Sofía, Tania, Ella, enamorada ya del escritor, tuvo en el primer tiempo que refrenar su sentimiento, un poco confuso dentro de su alma, y asistir a los paseos en que hacía de "partenaire» de su hermana, por la que el conde no sentía la menor atracción. La revelación del sentimiento afín, pues Tolstoy amaba ya a Sofía, lo ha relatado él mismo en una de sus obras. Poseído de él e incapaz de expresarlo, lo fijó en signos cabalísticos en la arena, durante un paseo familiar. Sólo acertó a poner las primeras palabras de su pregunta apasionada. En la misma forma respondió la que fué su esposa. Días después, formalizado ya el compromiso, él, para que Sofía lo conociera bien, le da a leer su diario, sus páginas vívidas de juventud, que naturalmente en ella produjeron una impresión descorazonante. "Lloré muchos días cuando conocí la juventud libertina de León», anota días antes de su matrimonio. De nada le sirvió a Tolstoy la desilusión que para mayor conocimiento infligió a su novia; ella siguió ignorándolo como antes, y temiéndolo más. Después del matrimonio, y partiendo al viaje de bodas, anota Sofía:

Yo estaba confusa y no podía librarme de un vago temor. No me atrevía a tutear a León Nicolaevich y evitaba llamarlo por su nombre. HHasta mucho tiempo después, seguí tratándolo de Ud.

No se libró la condesa de su temor, del miedo que le inspiraba el que ya era su marido, y siempre en el trascurso de su 
vida conyugal este miedo del día de bodas le angustió el espíritu.

El 8 de Octubre de 1862 reanuda la condesa su diario, interrumpido en los días del viaje de noviazgo, y en una larga anotación se refiere a sus sueños de juventud, los que a pesar de su matrimonio no han sido cumplidos. El recuerdo del tormentoso pasado de su marido la oprime, y negándose a abandonar sus ilusiones de quince años, exclama. «Todo su pasado es para mí tan terrible que temo no poder reconciliarme jamás con él» y el mismo día más adelante agrega: «Hoy día he sentido de golpe que él y yo tenemos cada uno nuestro camino independiente.» Si observamos que estas anotaciones han sido hechas quince días después del connubio, podemos confirmarnos en la idea de que entre ambos nunca hubo una intimidad total. Todo se oponía a ello, a pesar del común deseo de felicidad que a ambos embargaba. Naturalezas de contextura anímica distinta, él imperioso, orgulloso, dominante, vagamente sentimental e idealista; ella, también orgullosa y dominante, sólidamente asentada en la realidad burguesa en que el ideal se limitaba a la lechosa pureza de una familia larga, debían fatalmente marchar por "caminos independientes».

Al día siguiente contiene el diario una anotación extraña: «Todas estas relaciones carnales son repugnantes», y dos días después, los diez y ocho años de Sofía, en contacto reciente con las amargas realidades diarias, gritan su desperación en unas interrogantes que hoy día sólo nos hacen sonreír:

Mi marido no. me ama. ¡A qué vivir, cuando las cosas van tan mal, para mí y para los demás! Esta idea extraña me obsede.

Empiezan en ella sus dudas primeras acerca de la naturaleza del amor de su marido, y la aterroriza y la deprime la idea de ser sólo un objeto para satisfacer una pasión que considera, como toda pasión, efímera. No la halagaba la certeza de ser objeto de un sentimiento pasional. Quería, ante todo, fijar sus derechos de mujer y mantener el rango de su espíritu altivo e indomable, y el 23 de Noviembre del mismo año escribe en su diario:

La cuestión es muy simple. Si yo no lo intereso, si no soy más que una muñeca para él, más que una mujer, y no un ser humano, yo no quiero y no puedo continuar viviendo así.

Las posiciones, como se ve, eran muy claras, y las palabras transcritas parecen señalar la víspera de un combate, en que 
se niegan y se conceden favores y sentimientos, y no la anotación de los días plácidos de una pareja de novios. Seguramente Tolstoy, con mucha razón, no tomaría en cuenta los arranques de su joven mujer y los dejaría pasar como inevitable torrente sin importancia.

El recuerdo de los hechos conocidos en el diario de su marido le embarga el ánimo y no la deja un minuto. En los últimos días de 1862 anota un deseo intenso: « $i \mathrm{Si}$ yo pudiera quemar su diario y su pasado!» Se deja torturar por celos de todas las mujeres que han pasado en la vida de su marido, amoríos fáciles, mujeres lejanas que ella no conoció nunca y que para él acaso no fueron otra cosa que un recuerdo apasionado y placentero de los días hirvientes de su juventud.

El año 1863 en el diario de la condesa Tolstoy no es otra cosa que una sucesión de protestas vehementes del amor que siente a su marido. Se acusa de defectos inexistentes, y celos de todas y de todo la persiguen. Su espíritu de diez y ocho años quiere detener el minuto amoroso de la vida, y exige de su marido una consagración, total, en que su orgullo no puede aceptar situación alguna de inferioridad:

Amo terriblemente a mi marido-escribe el 6 de Junio de 1863-, pero lo que me irrita es que estoy colocada a su lado en una situación de inferioridad.

Y esto no lo puede soportar. Sin un freno sentimental que la contuviera, su ánimo cambiante se deja dominar por todos los síntomas del más conocido y más viejo de los histerismos, y a pesar de su talento innegable, anota frases en su diario que revelan un pesimismo de cliché, o una desesperanza prematura e infundamentada. Después del nacimiento de su primer hijo escribe:

Algo me dice que yo sufriré constantemente, creo que es el temor de no poder atender debidamente mis deberes con mi familia.

Y pocos días después, el 31 de Julio de 1863, se acentúa la distancia que la separa de su marido:

Está tan desagradable que lo evito todo el día. Cuando me dice. "Voy a dormir», pienso: «A Dios gracias»... Me parece que todo ha terminado. Estos diez meses de matrimonio han sido los más terribles de mi vida.

Todas sus frases revelan que la incomprensión de los esposos comenzó en el matrimonio mismo y durante la vida conyugal no hizo sino atenuarse y acentuarse, según las circunstancias. 
No ha habido, como afirman los historiadores, períodos fijos en la tortura cotidiana de la vida de Tolstoy y su esposa. La felicidad que soñaron ambos pasó junto a ellos, y tal vez no lo supieron nunca. En la numerosa familia que formaron, y en más de cuarenta años de vida conyugal, siempre fueron extraños que se temían y no se entendían. "Nuestras vidas se separan más y más», anota ella el 7 de Octubre de 1863, y pocos días después: "Se diría que de nuestro amor no queda nada...» Todo la rebela ante su marido. La influencia de su sentimiento del cual no puede liberarse; la insignificancia de su personalidad ante la de su esposo: siempre el orgullo de ambos cónyuges los diferencia en sus afecciones:

Mi existencia es de una trivialidad tal-escribe el 13 de Noviembre de 1863-que es la muerte misma. Empiezo a tenerle miedo y a sentirme totalmente extraña a él.

Así trascurren los años, con intermitencias que no borran la impresión de desconcierto en los sentimientos de los esposos. No hay abdicaciones ni de él ni de ella, y si en muchas ocasiones las quejas de Sofía pueden parecer grito de hembra joven insatisfecha, no es menos cierto que el espíritu inquieto de su marido, para el cual el amor a su esposa era una función mínima en su personalidad, arrancaba a la joven lamentos de un desconsuelo que no se quiere resignar y que llora su soledad. El 12 de Septiembre de 1867, cinco años después del matrimonio, escribe:

La verdad es que todo ha concluído. No queda sino un vacío inmenso y una manifiesta indiferencia... ¿Qué he sacado yo con $\mathrm{mi}$ amor? No he recogido sino sufrimientos y humillaciones. Tengo necesidad de su cariño y de su simpatía y no cuento con ellos. Padezco de un orgullo impotente, de un amor humillante del que nadie tiene necesidad y que me aniquila y me consume...

Y la queja sigue. Debemos anotar esta circunstancia dolorosa: siempre que el diario de la condesa se refiere a sus padecimientos o a sus alegrías, siempre que expone un sentimiento, que analiza un estado de ánimo, domina el tono de reproche, de queja, de tristeza. Parece que la vida le sonríe, y la hace feliz, cuando su espíritu no aparece en sus anotaciones, cuando el diario se transforma en un cuaderno de bitácora de los pequeños acontecimientos de una familia burguesa acomodada, y el alma, que no ha perdido, pues aun conserva destellos de juventud, es cierto que cada vez más lejanos, se encuentra como un poco desvanecida. Así pasan los años. Hay una ano- 
tación sin importancia en 1868, ninguna en 1869 , una en 1870 , otra en 1871, y ya en los años de $1872,73,74$ el diario se transforma en anotaciones menudas de hechos vulgares, sin interés alguno. El espíritu se ausenta, y así escribe el 9 de Abril de 1872: "Tiempo precioso. Se diría que estamos en verano", como cualquier persona que quiere iniciar una bostezante conversación social. En 1874 la muerte de uno de sus hijos, Petia, la hace reencontrar su alma perdida, y la soledad de su vida campesina la hace rebelarse contra su tristeza aposentada tantos años. Escribe el 12 de Octubre de 1875:

Esta vida solitaria en el campo termina por hacérseme insoportable. Una apatía, una indiferencia a todo y por todo. Hoy día, mañana, los meses, los años, siempre, siempre la misma cosa, iguales.

Y solo han pasado trece años de matrimonio y ella sólo cuenta treinta y un años. Pero ya ha podido comprender que las horas gloriosas de juventud se han esfumado y que la patriarcal quietud del matrimonio no tendría variante alguna en el resto de su existencia. Si alguna vez en un vuelco inesperado el corazón pudo reclamarle su hora de aventura, si el tedio irredimible de la vida hogareña pudo aparecérsele como un cilicio, no podemos dudar que confinó su única esperanza en el povenir de su familia y que aceptó para siempre esa «especie de muerte moral»-son sus palabras del día indicado-que es el matrimonio, y en ayudar a su marido y en educar a sus hijos puso todas sus esperanzas porque si "las gentes no esperasen no podrían vivir», agrega líneas más adelante.

Pasan los años, y ni sus burguesas ocupaciones familiares a las que se ha consagrado con todo. el afecto de su espíritu, sirven para hacerla perder su neurosis desengañada: "Cuán triste esta eterna lucha con los niños» anota el 15 de Septiembre de 1876 y al día siguiente: «Estoy en un estado de excitacion nerviosa tal, que me parece que me va a estallar la cabeza.» Ya de los sentimientos va quedando muy poco. E1 23 de Septiembre de 1878 escribe:

Décimosexto aniversario de nuestro matrimonio. He dado a los niños una lección de alemán que me ha salido bastante bien. El tiempo está calmado, dulce, claro. Andriucha me da muchas alegrías.

Como puede verse, no hay en el recuerdo del matrimonio ninguna evocación sentimental; nada que nos haga retornar ni remotamente a las anotaciones pasionales, exclusivamente pasionales, de los primeros años. Después el año 1878 sigue 
inventariado hasta en sus actos más insignificantes, y todas sus anotaciones se reducen a dolores de cabeza, resfriados de los niños, la enumeración de las liebres y torcazas que el conde trae a las comidas como botín de sus paseos, y querellas por asuntos materiales, de dinero, de hechos pequeños. El 9 de Octubre de 1878 exclama:

He tenido con Liovochka (1) una pelea terrible. Soy desgraciada, pero completamente inocente. Me odio a mí misma, mi vida y mi fantasiosa felicidad. Todo me aburre y me digusta.

Pocos días después, el 11 de Noviembre del mismo año:

Me hago el efecto ser una máquina en movimiento. Quisiera vivir un poco para mí y no tengo vida interior personal alguna... Pero no hablemos de esto... ¡Silencio!

Es bien triste comprobar el estado de alma de Sofía en esta época, que los críticos y estudiosos de la obra tolstoyana han calificado como de la suprema felicidad de ambos esposos. No sabemos, pero no queremos suponerlo así, si la felicidad conyugal consiste precisamente en la anulación total del espíritu de los cónyuges, y no creemos que cuando toda la vida común se reduce al cuidado de un resfriado o de un dolor estomacal, o al relato de la forma como se cocinaron las perdices que ha cazado el marido, la felicidad matrimonial se halle en su punto cenital.

El tiempo, que no perdona la felicidad ni el dolor, los va separando más si cabe. El 26 de Agosto de 1882 la condesa tiene treinta y ocho años, y escribe:

Hace veinte años, cuando era joven y feliz, comencé a escribir este diario y a contar la historia de mi amor por Liovochka. En esta páginas no hay casi nada más que amor. Hoy día, después de veinte años, he pasado la noche sola, llorando mi amor perdido.

El recuerdo indudablemente ha hecho ensoñar a la condesa quimeras desvanecidas. Hemos visto que en su diario el amor es versátil, cambiante, y que fuera de él hay muchas cosas, una serie de pequeños sentimientos, que creemos fueron amenguando con el rodar de los días iguales. Mucho antes de los veinte años de matrimonio, el amor que los llevó a los altares se había perdido. Ni él ni ella lo sentían. Ya el conde ha ma-

(1) León Nicolaevich, su marido. 
nifestado deseos de irse, y la condesa por más que se empeña en engañarse, tiene que confesar:

Me ha sido imposible probarle el fervor con que lo quiero después de veinte años, hoy como el primer día.

Ni ella podía creer de buena fe esa piadosa mentira después de sus anotaciones en el diario que hemos visto, ni él, por ser mentira, podía aceptarla. Ya en este año de 1882 empieza la era de la infelicidad del matrimonio, según los críticos. A fines de 1881 la familia se ha establecido en Moscú para la educación de los hijos, y el conde dominado, de día en día más por sus ideas místicas y humanitarias, se aleja de la sociedad, del mundo, y se siente molesto con la gloria de sus obras de arte. Quiere a toda costa democratizarse. en el más incómodo sentido de la palabra: alternando con gente inculta, desaseada, grosera, inferior. Y esto, naturalmente, no hace sino acrecentar la distancia que separa a los esposos, apartar aun más los caminos independientes que en la quincena siguiente a las bodas previó la condesa que seguirían por toda la vida sus almas lejanas, separadas en plena intimidad.

El 25 de Octubre de 1886 anota:

Estoy condenada a ser una verdadera calamidad. Este es el papel que me asignan en casa mi marido y mis hijos... El me ha dado a entender que no le soy necesaria y de nuevo estoy relegada a la categoría de un objeto superfluo.

Ante las tendencias místicas y evangélicas de su marido toma una actitud de fiera independencia y anota rabiosamente en su diario:

¿Por qué quiere que renuncie a toda vida personal y que sufra constanmente con el espectáculo de la miseria y del infortunio de los demás?

Las preguntas siguen en su vida y no precisamente para unirla a su esposo. El 26 de Octubre del mismo año: «¿Por qué he dejado de creer en sus condiciones de escritor?» E1 abismo no hace sino crecer.

El 20 de Noviembre de 1890 la condesa tiene 46 años y una larga anotación desgarrada consigna el fracaso de su matrimonio, el vacío de su vida que creyó llenar con los hijos, con los deberes y las obligaciones de la moral burguesa:

Liovochka ha roto toda relación conmigo... En él no hay nada más que sensualidad... ¡ $\mathrm{Si}$ solamente uno, alguien siquiera me testimoniara 
un poco de simpatía! Los días, las semanas, los meses pasan, y León y yo no cambiamos una sola palabra.

Pocos días después: "Qué horas tan penosas estoy viviendo en mi vejez.» Su única labor es copiar el diario de su marido, y esta labor no la reconcilia con él en lo más mínimo. El 20 de Diciembre de 1890 escribe:

«No habiendo copiado hoy día el diario de mi marido, me siento más pura y más serena.» Al transcribir una frase de Tolstoy sobre el amor que figura en su diario, de un crudo materialismo, la condesa escribe:

Si 29 años atrás hubiera conocido esto, no habría contraído matrimonio con León Tolstoy.

A una vida sufrida en los términos que hemos visto se une en estos últimos años un decaimiento general de la salud, y la última anotación del diario, 23 de Enero de 1891, termina: "Mi mal estado de salud me vuelve idiota.»

Con los datos consignados no podemos seguir afirmando que en el matrimonio de Tolstoy hubo períodos de felicidad y períodos de desgracia. La incomprensión y la distancia de los dos caracteres se manifestó desde los primeros momentos y el amor que ella soñaba y sobre el cual él escribió páginas inmortales, fué, pasados los inevitables transportes pasionales, un recuerdo fugaz y $\sin$ vida. Es interesante conocer el concepto del sentimiento amoroso que tenía el conde, pero ello demandaría un estudio de una extensión que aquí no podemos emprender y que acaso algun día realicemos. Un estudio que muestre cómo cambió el hombre que escribió la Felicidad Conyugal (1857) sin ser casado. y cómo después de veintiocho años de connubio escribió la imperecedera Sonata a Kreutzer. Sea lo que haya sido en el alma del conde, su mujer sólo conoció los aspectos más tristes de la vida, y su vida conyugal, a la que dedicó sus más puros sentimientos, sus más intensas energías, no fué sino un continuado fluir de lágrimas. - A B E L VALDÉS A. 